\title{
Evaluation of metallic stents for malignant ureteral obstruction- a single institution experience
}

\author{
Shah $B^{1}$, Chaudhari $R^{2}$, Sharma $S^{3}$, Gupta $A^{1 *}$ and Kant $S^{4}$ \\ ${ }^{1}$ Department of Urology, Ruby Hall Clinic, Pune \\ ${ }^{2}$ Department of Urology, Consultant, Ruby Hall Clinic, Pune \\ ${ }^{3}$ Department of Urology, Consultant, Aims, Raipur \\ ${ }^{4}$ Department of Urology, Gokul Hospital, Rajkot
}

*Corresponding author: Gupta A, Department of Urology, Ruby Hall Clinic, 40

Sasoon Rd, Sangamvadi, Pune, Maharashtra 411001, India.

Received Date: October 27,2020

Published Date: December 11, 2020

\section{Abstract}

Introduction: Ureteral obstruction caused by extrinsic compression is commonly associated with intra-abdominal malignancy. Internal drainage with ureteral stents is typically the first-line therapy to relieve such obstructions. The limitation of polymeric ureteral stents in patients is that they get easily compressed and recurrence of obstruction is seen very quickly. The metallic stents were introduced to improve the patency rates of patients with chronic upper urinary tract obstruction, obviating the need for frequent stent exchanges. We report our clinical experiences with the use of metallic ureteral stents in the management of poor ureteral drainage due to extrinsic malignant obstruction/compression.

Materials and methods: In this study, we described the functional outcomes of a Resonance metallic ureteral stent in patients with malignant ureteral obstruction done during August 2016 till August 2018. Stent failure was detected by clinical symptoms, imaging studies, and renal function tests. The functional duration of each stent was calculated.

Results: A total of 27 stents were successfully inserted in 20 patients with malignant ureteral obstruction. After insertion of metallic stents, hydronephrosis subsided or remained stable in $89 \%$ of the ureteral units. Serum creatinine decreased or remained stable in $90 \%$ of these patients. In $15 \%$ ureteric units metallic stents were required to be removed or changed.The Resonance stent exhibited a mean increase in functional response at minimal 1year follow up.

Conclusion: Our results indicate that metallic ureteral stent placement is a technically feasible procedure with minimal complications, increased longevity and is well tolerated among patients.

Keywords: Malignant ureteric obstruction; Metallic ureteric stents; Polyurethane DJ stent; PCN

Abbreviations: MUO-Malignant ureteric obstruction; PCN- Per cutaneous nephrostomy; MRI- Magnetic resonance imaging; QOL-Quality of life

\section{Introduction}

MUO(Malignant Ureteric Obstruction) can result from extrinsic compression by a primary lesion, metastases, retroperitoneal lymphadenopathy or direct tumor invasion [1].The median life expectancy of patients with metastatic cancer that causes ureteral obstruction is generally less than one year [2]. Malignant ureteral obstructions require immediate ureteral drainage in order to salvage renal function [3]. Reduced renal function makes patient ineligible for chemo therapy or any additional treatment. Management options involve either PCN (Percutaneous Nephrostomy) or internal drainage with polyurethane stents. Conventional Polyurethane DJ stents have high failure rates and significant complications. PCN is commonly used as an alternative to DJ stent. PCN is more 
invasive than double-J stent insertion and have greater incidence of accidental tube dislodgement. The invasiveness of the procedure and the high incidence of tube dislodgement results in seriously compromised quality of life [4]. It also affects patient's ambulation and mobility. Novel designs of ureteral stents made of different materials have been invented with the aim of achieving better drainage. Although segmental metal mesh stents initially seemed promising, the long-term results have not been satisfactory [2]. Full length metallic stents (Resonance stent) have been introduced for MUO management. Resonance is double-pigtail stent moulded from corrosion resistant alloy of Nickle, Chromium, Titanium, Molybdenum. It forms tightly coiled spiral with no end holes [1] Secondary to their metal composition these stent have been shown to be more resistant to external compression than conventional polyurethane DJ stent [4]. We herein describe our initial experience with Resonance metallic stent in context of patient with MUO. As there are no end holes in metallic stent urinary drainage occurs through side of the stent, through the continuous ridge (Figures $1,2)$.

Figure 1: Metallic Stent.
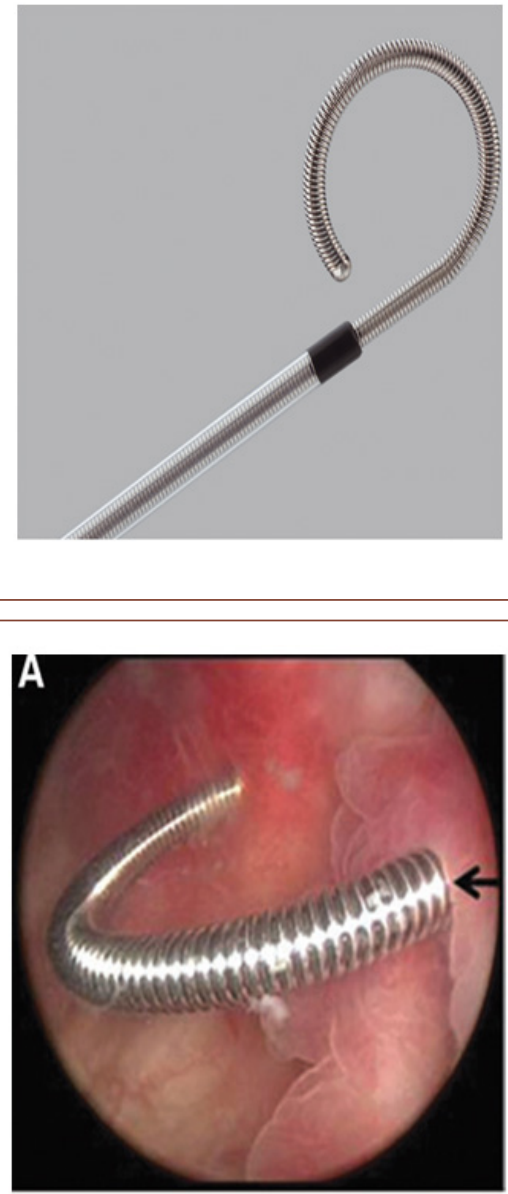

Figure 2: Cystoscopic View of Metallic Stent.

\section{Materials and Methods}

Retrospective study was conducted between Aug 2016 and Aug 2018. During this period we posted 45 patients presented with MUO to us in Ruby Hall Clinic, Pune. Out of these in only 27 patient retrograde guidewire insertion was possible and of these, only in 20 patients metallic stents (RES; Cook Urologic) could be inserted. In 7 patients, stents were inserted bilaterally. Thus total of 27 metallic stents were inserted. Patients were either newly diagnosed with MUO or had a prior diagnosis of same. Obstruction was diagnosed by clinical signs, increasing azotemia, or incidentally through routine cancer surveillance imaging. Diagnosis was confirmed with few of the following tests- ultra sonography, computed tomography, magnetic resonance imaging (MRI), and diuretic renal scintigraphy. Stents were inserted only if renal function was compromised. The decision to place metallic stents was based on patient is comorbidities, cancer prognosis, and need for additional chemotherapy [4]. After an initial cystoscopic examination of the bladder, retrograde pyelography was performed in all patients to define the obstructed ureteral segment. A hydrophilic glide wire was then negotiated past the point of obstruction and advanced into the kidney under fluoroscopic visualization. The metallic stent introducer system was then passed over the super stiff wire with the outer $8.3 \mathrm{~F}$ sheath radio-opaque tip positioned at the UPJ. The wire and the inner introducer catheter were removed, leaving the 
outer sheath in place. The metallic stent was then placed through the sheath and advanced proximally using the previous introducer as a pusher. Importantly, the metallic stent does not have an inner lumen and is not passed over a wire. When the proximal curl of the stent is seen beyond the tip of the sheath in the renal pelvis, the sheath is slowly removed, keeping the inner catheter in place. The outer sheath is completely removed when the distal curl is seen deployed within the bladder. Finally, correct intravesical positioning is confirmed with cystoscopy, making any adjustments if necessary with flexible graspers. All patients were prospectively followed postoperatively for resolution of symptoms and azotemia. Patients were also assessed at 6 months with sonography to evaluate for hydronephrosis. Lastly, stent failures, complications, and mortality were recorded.

\section{Results}

Out of the total 45 patients stent insertion could be possible in only 20 patients, while 7 patients had done stenting bilaterally. Out of 20 patients 7 were men (35\%) and 13 were women (65\%). The mean age was $55.2 \pm 22.3$ years. Cervical cancer was the most frequent type of malignancy ( 6 patients), followed by Bladder ( 4 patient) and colorectal cancer ( 3 patients). Bilateral stent was introduced in 3 patients of Ca cervix, 2 patients of Ca Bladder, 1 patient of CA prostate and 1 patient of colorectal carcinoma. After 1year of follow up, 18 patients (90\%) were alive and 2Patients $(10 \%)$ had died. The stent failure rate in our experience was $10 \%$. This is because stenting resulted in failure to successfully relieve hydroureteronephrosis in 3 ureteral unit by metallic stent $(3 / 27)$. Success rate of initial retrograde insertion was $60 \%$, with no intraoperative complications. Urine culture sensitivity was performed within the first14 days post-operatively in al patients. 18 (90\%) showed no infection, one Urine culture showed E. coli (patient with poorly-controlled diabetes) and one grew Pseudomonas aeruginosa (patient with an indwelling Foleys catheter). These required oral antibiotic treatment. In all patients sterile urine was confirmed later. Out of 27 inserted stents, 2 stents were removed due to worsening hydronephrosis and 1 stent was removed due to severe stent induced cystitis. Majority of stents $(90 \%)$ successfully relieved or stabilized hydroureteronephrosis on subsequent imaging (ultrasound or CT or MRI). Success rate of stent was based on pre and post metallic stent hydronephrosis, serum creatinine level and symptomatic improvement (Table 1).

We have done metallic stent insertion only in terminally ill patients. Therefore our criteria for patency rate (success rate) also includes

1. No change of stent required till death of patient.

2. If patient tolerated stent with or without medical support

\section{Discussion}

Deficiency in upper tract drainage is a frequent problem encountered in routine urologic practice today. Conventional approach in the management of chronic severe ureteral obstruction have been to place percutaneous nephrostomy drainage, PCN significantly decreases quality of life of the patient ailing from their malignancy [5]. In addition, polymer ureteral stents have been used but they had disappointing results due to the frequency of stent exchanges (approximately every 2- 3 months), stent encrustation, and external compression [5]. Failure rates for traditional polymer stents in the setting of malignant ureteral obstruction are estimated to be between 40-60\% [5]. Metallic ureteral stents have been studied in a limited number of retrospective studies. Published figures for stent failure from case series' of greater than fifteen patients vary from 16-35\% [6]. Our results show a failure rate of these stents of only $11 \%$ exemplifying their clear benefit. Currently, metallic ureteral stents are indicated that they can be left in situ for up to 12 months and longer [5]. The use of metallic ureteral stents in the setting of deficient ureteral drainage obviates the need for an exchange. In addition, metallic ureteral stent placement procedures had minimal complications and were well tolerated by patients. Some patients complained of mild flank pain and/or dysuria directly after stent placement. This phenomenon was usually self-limiting, and probably due to expanding forces of the endoprosthesis [7]. Goldsmith et al. described subcapsular hematoma formation following metallic stent placement in $12 \%$ of their study cohort. They argued that this was likely "related to the excessive length of the inner cannula relative to the outer sheath in the supplied introduced system [8]. In our single institution study, we did not experience any such complications and recommend gentle manipulation of the upper tracts after properly done retrograde contrast studies during stent placement to avoid this issue. To help predict treatment success or failure, we based our research on previously published peer reviewed scientific literature. As previously shown by Ganatra et al., the type of underlying malignancy did not predict stent success or failure in our series [9]. Ganatra et al. also reported that gross tumor invasion noted at cystoscopy was a significant risk factor for stent failure and requirement of percutaneous nephrostomy ( $\mathrm{p}$ $=0.008$ ) [9]. It is also the most common cause in failure to insert guidewire. These bladders have a very low bladder capacity due to invasion by tumor, making guide wire insertion difficult due to poor vision. In addition, Goldsmith et al. reported that prostate cancer invading the bladder was a risk factor for stent failure [8]. Bladder invasion was not specifically assessed as a risk factor for stent failure in our study. Wang et al. also showed that patients who had received previous radiation therapy had a significantly lower stent patency rate than those who did not receive previous radiation therapy. They hypothesized that radiation therapy causes ureteral fibrosis and impairs ureteral peristalsis, ultimately leading to more encrustation and a smaller ureteral lumen [10-13]. Other studies nevertheless, have shown no difference in stent patency rates whether or not patients had received radiation therapy [6] (Table 2). 
Table 1: Functional outcome of patient and metallic stent.

\begin{tabular}{|c|c|c|c|}
\hline Criteria & \multicolumn{2}{|c|}{ Stable } & Delayed Increase \\
\hline Serum Creatinine & Decreased & 5 & 2 \\
\hline No of patient & 13 & 25 & 10 \\
\hline$\%$ & 65 & Improved/Stable & Delayed Worsen \\
\hline Hydronephosis on Imaging & Resolved & 5 & 3 \\
\hline Ureteral unit & 19 & 18.5 & 11.1 \\
\hline$\%$ & 70.4 & Decrease & Delayed Worsen \\
\hline Symptoms & Asymptomatic & 3 & 3 \\
\hline No of pt & 14 & 15 & 15 \\
\hline
\end{tabular}

Table 2: Comparison of various study on metallic stent with our study in term of stent patency rate, complication, and management.

\begin{tabular}{|c|c|c|c|c|c|}
\hline Study & No of Stents(benign/malignant) & Follow Up(months) & Patency Rate & Complication & Management of Complication \\
\hline \multirow{6}{*}{$\begin{array}{c}\text { Nagele et } \\
\text { al. [11] }\end{array}$} & \multirow{6}{*}{$18(5 / 13)$} & B-11.6 & B-75\% & $\begin{array}{l}\text { Urinary tract infec- } \\
\text { tion } x 6\end{array}$ & Antibiotics \\
\hline & & \multirow{5}{*}{ M-7.3 } & \multirow{5}{*}{ M- $46 \%$} & $\begin{array}{l}\text { Recurrent infections } \\
\mathrm{x} 1\end{array}$ & Stent removal Stent \\
\hline & & & & $\begin{array}{l}\text { Persistent hematu- } \\
\text { ria x1 }\end{array}$ & removal Not reported \\
\hline & & & & Encrustation $\times 2$ & Stent removal \\
\hline & & & & $\begin{array}{l}\text { Severe dysuria and } \\
\text { pain } \times 2\end{array}$ & Stent removal \\
\hline & & & & $\begin{array}{l}\text { Insufficient drainage } \\
\text { x } 4\end{array}$ & Nephrostomy \\
\hline \multirow{6}{*}{$\begin{array}{l}\text { Modi et } \\
\text { al. [12] }\end{array}$} & \multirow{6}{*}{$\begin{array}{l}\text { 69(19/50) } 76 \text { stents when includ-ing } \\
\text { stent exchanges }\end{array}$} & \multirow{6}{*}{$\begin{array}{l}5(0-18) \text { months } \\
\text { Mean }\end{array}$} & $\begin{array}{l}\text { Overall 57\%, } \\
\text { >12 months in- } \\
\text { dwelling } 36 \% \text {, }\end{array}$ & Encrustation $\times 3$ & $\begin{array}{l}\text { Cystolithoapaxy or percuta- } \\
\text { neousnephrolithotomy }\end{array}$ \\
\hline & & & \multirow{5}{*}{$\begin{array}{l}\text { MSs for PSs } \\
\text { replace- } \\
\text { ment-37\% }\end{array}$} & Tissue ingrowth $\mathrm{x} 1$ & Percutaneous stent removal \\
\hline & & & & $\begin{array}{l}\text { Obstructed stents } \\
\text { x15 }\end{array}$ & Stent removal \\
\hline & & & & Migration x 1 & Stent removal \\
\hline & & & & $\begin{array}{l}\text { Urinary tract infec- } \\
\text { tion } x 8\end{array}$ & Stent removal \\
\hline & & & & Stent Failure & $\begin{array}{l}\text { Stent removal when stent failure } \\
\text { Observation }\end{array}$ \\
\hline $\begin{array}{l}\text { Garg et } \\
\text { al. [13] }\end{array}$ & 10(8/2) Ureteroenteric & Up to 12 months & $12.50 \%$ & Migration x 9 & $\begin{array}{l}\text { Stent removal and polymeric } \\
\text { stent insertion }\end{array}$ \\
\hline \multirow{3}{*}{$\begin{array}{l}\text { Gold- } \\
\text { smith et } \\
\text { al. [8] }\end{array}$} & \multirow{3}{*}{$37(-/ 37)$} & \multirow{3}{*}{ Up to 12 months } & \multirow{3}{*}{$65 \%$} & Migration x 3 & Observation or stent exchange \\
\hline & & & & $\begin{array}{l}\text { Progressive hydro- } \\
\text { nephro- sis x } 9\end{array}$ & Stent removal or exchange \\
\hline & & & & $\begin{array}{l}\text { Subcapsular renal } \\
\text { hemat- omax3 }\end{array}$ & Conservative \\
\hline \multirow{3}{*}{$\begin{array}{l}\text { Our } \\
\text { study }\end{array}$} & \multirow{3}{*}{$27(-/ 27)$} & \multirow{3}{*}{$>12$ months } & \multirow{3}{*}{$85 \%$} & UTIx2 & Antibiotics \\
\hline & & & & $\begin{array}{l}\text { Persistant hydrone- } \\
\text { phrosisx2 }\end{array}$ & Stent removal \\
\hline & & & & $\begin{array}{l}\text { Stent induced cys- } \\
\text { titisx } 1\end{array}$ & Stent removal \\
\hline
\end{tabular}

Metallic ureteral stents, when used in managing poor ureteral drainage, not only improved quality of life, but also is a cost-saving service. Despite the initial higher cost of the individual metallic stent versus traditional polymer ureteral stents, we report fewer surgical procedures (i.e. stent exchange) needed, which accounted for this cost difference. The overall cost reduction was estimated to be between $56.4 \%$ and $59.5 \%$ per patient/year, not taking into account other cost savings, including reduced post-operative office visits, fewer follow-up imaging studies, and any unforeseen operative complications [5]. We recognize several limitations to 
the present study, including the retrospective constitution of this single institution study design and smaller sample size. Whereas our database continues to expand, this is at a relatively slow rate given that metallic stenting is still on the whole reserved for a select group of patients. We hope that changing clinicians' thinking through this critical analysis of the safety, efficacy and tolerability of this stent will lead to a larger number of patients being made eligible for these procedure.

\section{Conclusion}

Metallic ureteral stent placement is a technically feasible procedure with minimal complications and is well tolerated among patients. Metallic stents can be left in situ for longer durations. They provide a significant financial benefit when compared to frequent polymer stents replacements. Preference to metallic stent insertion instead of PCN also significantly reduces the morbidity and improves overall QOL of terminally ill patients.

\section{Acknowledgment}

None.

\section{Conflict of Interest}

No conflict of interest.

\section{References}

1. Elsamra SE, Leavitt DA, Motato HA, Friedlander JI, Siev M, et al. (2015) Stenting for malignant ureteral obstruction: Tandem, metal or metal mesh stents. Int J Urol 22(7): 629-636

2. Chow PM, Chiang IN, Chen CY, Huang KH, Hsu JS, et al. (2015) Malignant ureteral obstruction: Functional duration of metallic versus polymeric ureteral stents. PLoS One 10(8):1-10.
3. Kim JH, Song K, Jo MK, Park JW (2012) Palliative care of malignant ureteral obstruction with polytetrafluoroethylene membrane-covered self-expandable metallic stents: Initial experience. Korean J Urol 53(9):625-631.

4. Abbasi A, Wyre HW, Ogan K (2013) Use of full-length metallic stents in malignant ureteral obstruction. J Endourol 27(5): 640-645.

5. Baumgarten AS, Hakky TS, Carrion RE, Lockhart JL, Spiess PE (2014) A single-institution experience with metallic ureteral stents: a costeffective method of managing deficiencies in ureteral drainage. Int Braz J Urol 40(2):225-231.

6. Patel C, Loughran D, Jones R, Abdulmajed M, Shergill I (2017) The resonance $\AA$ metallic ureteric stent in the treatment of chronic ureteric obstruction: a safety and efficacy analysis from a contemporary clinical series. BMC Urol 17(1):16.

7. Kallidonis P, Goulimi E, Ntasiotis P, Panagopoulos V, Liatsikos E Experience with resonance stent. Hell Urol 28(2).

8. Goldsmith ZG, Wang AJ, Bañez LL, Lipkin ME, Ferrandino MN, et al. (2012) Outcomes of metallic stents for malignant ureteral obstruction. J Urol 188: 851-855.

9. Ganatra AM, Loughlin KR (2005)The management of malignant ureteral obstruction treated with ureteral stents. J Urol 174(6): 2125-2128.

10. Wang HJ, Lee TY, Luo HL, Chen CH, Shen YC, et al. (2011) Application of resonance metallic stents for ureteral obstruction. BJU Int 108(3): 428432.

11. Nagele U, Kuczyk MA, Horstmann M, Hennenlotter J, Sievert KD, et al. (2008) Initial clinical experience with full length metal ureteral stents for obstructive ureteral stenosis. World J Urol 26(3): 257-262.

12. Modi AP, Ritch CR, Arend D, Walsh RM, Ordonez M, et al. (2010) Multicenter experience with metallic ureteral stents for malignant and chronic benign ureteral obstruction. J Endourol 24(7): 1189-1193.

13. Garg T, Guralnick ML, Langenstroer P, See WA, Hieb RA, et al. (2010) Resonance metallic ureteral stents do not successfully treat ureteroenteric strictures. J Endourol 23(7): 1199-1202. 